\title{
A Study on Antioxidant Property of Organic and Conventional Tomatoes
}

\author{
Vaijayanthi Kanabur* and Dr R. P. Lalitha Reddy** \\ *Assistant Professor and ** Associate Professor \\ Department of Food and Nutrition, Smt.VHD Central Institute of Home Science, Bangalore 1
}

\begin{abstract}
Tomato is one of the commonly consumed vegetables with high antioxidant capacity. The objective of the present study is to compare the antioxidant property of organic and conventional tomatoes. For the experiment, organic samples were procured from Era Organic Foods, (IMO Certified) Bangalore. Same variety of conventional tomato was obtained from same agro climatic zone. The samples were freeze dried using a lyodryer (LT5BC ISI lyphilization system, USA) and stored at $4{ }^{\circ} \mathrm{C}$ in dark. The tomato extract was prepared in a solvent consisting of methanol (69\%), ethanol (20\%), $\mathrm{HCl}(10 \%)$ and water (1\%). Total antioxidant capacity was estimated using Free Radical scavenging activity using 2, 2 Diphenyl-1-picryl hydrazyl (DPPH), $\beta$ Carotene bleaching method, Linoleic acid emulsion system-thiocyanate method and Ferric-reducing antioxidant power(FRAP) methods. The results reveal that organic tomatoes have higher antioxidant ability than conventional tomatoes. These differences are significantly higher in case of DPPH method, $\beta$ Carotene bleaching method but not significant in case of Linoleic acid emulsion system-thiocyanate method and Ferricreducing antioxidant power method.
\end{abstract}

Key words: Organic, Conventional, DPPH method, $\beta$ Carotene bleaching method, Linoleic acid emulsion system-thiocyanate method, Ferric-reducing antioxidant poer (FRAP)

\section{Introduction}

Free radicals are generated by the human body during the normal course of metabolism. Cellular damage arising from these free radicals is one of the fundamental mechanisms underlying a number of human neurodegenerative disorders such as diabetes, cancer, coronary heart diseases and aging. Halliwell (1996) ${ }^{[1]}$ has rightly pointed out that the balance between oxidants and antioxidants decides the health and vigour of a person.

Antioxidants can be natural or synthetic. Unlike synthetic antioxidants, natural antioxidants are safe and do not have side effects. The adverse effects of reactive species such as oxygen and nitrogen on normal physiological function are significantly reduced by dietary antioxidants (Panel on dietary antioxidants and related compounds, National Academy of Sciences, Washington DC 2000).

The total antioxidant capacity of a plant is influenced by soil type, soil chemistry, plant nutrients, climatic conditions, pest pressure. Organic foods are produced without using chemicals during production, processing or storage. There are two reasons for assuming that organic foods have higher amounts of phytonutrients compared to conventionally grown foods. 1) When a plant is attacked by pests, it triggers a plant defence mechanism and brings about synthesis of phytonutrients. These phytonutrients, which are often antioxidants, are beneficial both to the plant's health as well as human health. 2) Chemical fertilizers used in conventional agriculture increase plant growth, resulting in a decrease in the production of secondary plant metabolites like phytochemicals.

Tomato is the world's largest vegetable crop after potato and sweet potato. India produces 86 lakh tones of tomato every year and this forms $8.5 \%$ of the total vegetable production (Ministry of agriculture, NHB report). Tomato is a good source of potassium, folate, vitamin A, C and E. and Phytochemicals-carotenoids such as lycopene, $\beta$ Carotene, phytoene, phytofluene are found in abundance in tomato(Kirstie C A et al (2005) ${ }^{[2]}$. According to FAO per capita consumption of tomato is has increased from $4.42 \mathrm{~kg} / \mathrm{annum}$ to $6.63 \mathrm{~kg} / \mathrm{annum}$ between 1991 and 2004. Moreover tomato is commonly consumed by all sections of people and is available throughout the year. In this study an attempt is made to compare the antioxidant property of organic and conventional tomato.

\section{Materials and Methods:}

Selection of the sample: Organic tomato (Lycopersiconesculentum) variety Roma was procured from Era Organic Foods, (IMO Certified) Bangalore. Same variety of conventional tomato was obtained from same agroclimatic zone. The samples were freeze dried using a lyodryer (LT5BC ISI lyphilization system, USA) and stored at $4^{\circ} \mathrm{C}$ in dark. All other chemicals were of the analytical grade (Sigma, Himedia, Qualigens, Boisar, Ranbaxy). 
Various chemical constituents such as alanine, $\beta$ Carotene, lycopene contribute to the total antioxidant capacity of tomato(www.nal.usda.gov/fnic/food comp/data). Some of these are soluble in water and others are soluble in fat. So a mixture of solvents was used for estimation of total antioxidant capacity. The solvent used for extraction consisted of methanol (69\%), ethanol (20\%), $\mathrm{HCl}(10 \%)$ and water (1\%).

Extract Preparation: A flow chart describing the preparation of tomato extract is given in Fig 1

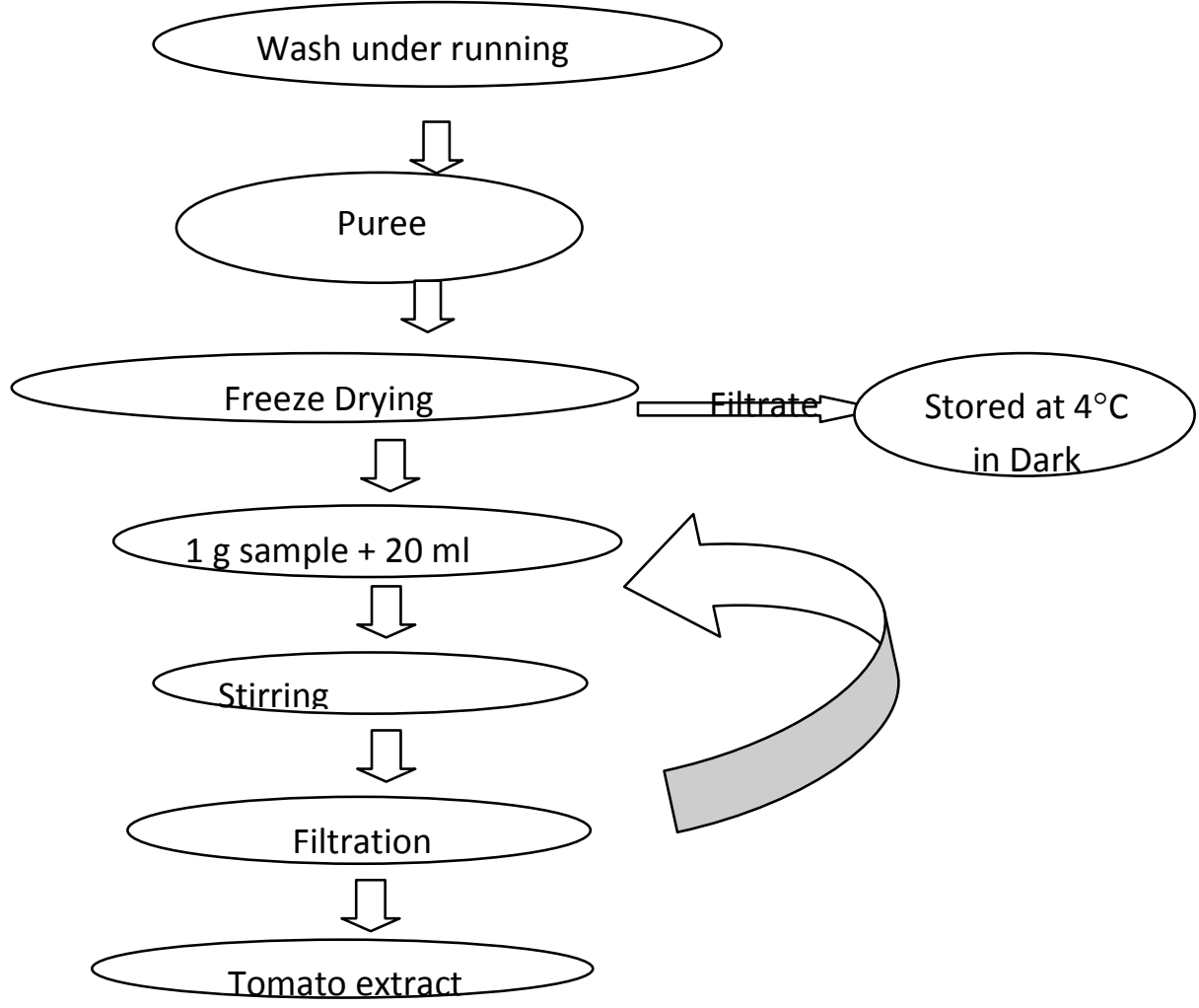

Fig 1: Procedure for the preparation of tomato extract.

Percent solid matter: Fresh organic and conventional tomato samples were weighed and lyophilized to dryness for 20 hours. The percent solid matter was calculated from the ratio of wet to dry.

Total Antioxidant Capacity Estimation: No single assay can measure all the antioxidation reactions. Therefore 2 or more methods of assay are more reliable indicators of antioxidant activity. The following methods were used for estimation.

Free Radical scavenging activity using 2, 2 Diphenyl-1-picryl hydrazyl (DPPH): The ability of antioxidants to reduce DPPH was assed according to the procedure described by Espin $(2000)^{[3]} .0 .1 \mathrm{mM}$ of DPPH in Methanol was incubated with varying concentrations of test compounds in different dilutions. The reaction mixture was incubated for 20 minutes at room temperature in dark and the absorbance of the resulting solution was read at $517 \mathrm{~nm}$ against a blank using a spectrophotometer (Shimadzu model UV Mini 1240). Free radical scavenging ability of the sample was calculated according to the following equation.

DPPH radical scavenging activity $(\%)=\{($ Abs Control-Abs Sample $) /$ Abs of Control $\}$ X 100. Gallic acid was used as a standard. All the analyses were carried out in triplicate.

$\beta$ Carotene bleaching method(Hidalgo et al 1994) ${ }^{[4]}: 0.2 \mathrm{mg}$ of $\beta$ Carotene, $20 \mathrm{mg}$ of linoleic acid and $200 \mathrm{mg}$ of Tween 20 were mixed in $0.5 \mathrm{ml}$ of chloroform and Chloroform was allowed to evaporate. $50 \mathrm{ml}$ of oxygenated water was added to this emulsion. To $4 \mathrm{ml}$ of this emulsion, $0.2 \mathrm{ml}$ of the test sample was added. Gallic acid was used as a standard. The control consisted of $4 \mathrm{ml}$ of the emulsion and $0.2 \mathrm{ml}$ of the solvent without the test sample. The tubes were covered with aluminium foil and were maintained at $50^{\circ} \mathrm{C}$ in a water bath. Absorbance was taken at $470 \mathrm{~nm}$ at zero time and after every 30 minutes for 2 hours or until the colour of $\beta$ Carotene disappeared. All the determinations were carried out in triplicate. Antioxidant activity was calculated using the formula 
Antioxidant activity $(\%)=100\left\{1-(\mathrm{A} \circ-\mathrm{At}) /\left(\mathrm{A}^{\circ}{ }^{\circ} \mathrm{O}-\mathrm{A}^{\circ} \mathrm{t}\right)\right\}$ where $\mathrm{A} \circ$ and $\mathrm{A}{ }^{\circ}$ absorbance values measured at zero time of the incubation of the test sample and control respectively. At and $\mathrm{A}^{\circ} \mathrm{t}$ are the absorbance measured in the test sample and control respectively after incubation for 120 minutes.

Linoleic acid emulsion system-thiocyanatemethod (Haraguchi, Hashimoto and Yegi, 1992 ${ }^{[5]}$ : Yen \& Hsieh, $1998)^{[6]}$. The reaction mixture consisted of $0.28 \mathrm{~g}$ of linoleic acid, $0.28 \mathrm{~g}$ of Tween 20 and $50 \mathrm{ml}$ of phosphate buffer (0.2 M, pH 7.0). To $2.5 \mathrm{ml}$ of this emulsion, $0.5 \mathrm{ml}$ of test sample and $2.5 \mathrm{ml}$ of phosphate buffer ( $\mathrm{pH} 7.0$, $0.2 \mathrm{M}$ ) were added and incubated at $37^{\circ} \mathrm{C}$ for 120 hours. The mixture prepared as above without the test sample served as the control. Gallic acid was used as a standard. The readings were taken after every 24 hours.

$5 \mathrm{ml}$ of $75 \%$ ethanol was mixed with $0.1 \mathrm{ml}$ of ammonium thiocyanate (30\%), $0.1 \mathrm{ml}$ of the above mixture, and $0.1 \mathrm{ml}$ of Ferrous Chloride $(20 \mathrm{mM}$ in $3.5 \% \mathrm{HCl})$ and allowed to stand at room temperature. Precisely after 3 minutes after the addition of ferrous chloride, the absorbance at 500nm was measured. Antioxidant activity in terms of percent inhibition was calculated as follows

$\%$ Inhibition $=\{1-($ Absorbance of the sample $) /$ Absorbance of the Control $)\} \times 100$

Ferric-reducing antioxidant power (FRAP): This was measured following the procedure originally described by Benzie and Strain $(1996)^{[7]}$. Samples in the range of 2 to $10 \mu 1$ were added to $900 \mu$ l of FRAP reagent. FRAP reagent consists of the following: $0.3 \mathrm{M}$ acetate buffer, $\mathrm{pH} 3.6,10 \mathrm{~m} \mathrm{M}$ TPTZ in 40mM hydrochloric acid and $20 \mathrm{mM}$ ferric chloride in $40 \mathrm{~m}$ M hydrochloric acid.

All the above were mixed in the ratio of 10:1:1(v/v/v) to obtain FRAP reagent. The reagent was preheated to $38^{\circ} \mathrm{C}$ and the initial absorbance was measured using acetate buffer blank. The reaction mixture was shaken vigorously for $15 \mathrm{sec}$ and incubated at $27^{\circ} \mathrm{C}$ for $90 \mathrm{~min}$. The absorbance was measured at $593 \mathrm{~nm}$ at the end of $90 \mathrm{~min}$. Control experiments without the sample or TPTZ were carried out to exclude the effect of the added test compounds. Higher absorbance indicates higher ferric reducing power. The results are expressed as Trolox equivalent reducing power.

Statistical analysis: Suitable statistical methods such as t test, paired t test were used to interpret the results. Tests were considered statistically significant at $\mathrm{p}<0.05$.

\section{Results and Discussion}

Percent Solid matter: The samples were freeze dried using Lyodryer LT5B ISI lyophilization System INC USA for 20 hours and Solid matter was calculated as a ratio of wet weight to dry weight.

Table 1:Percent solid matter in organic and conventional tomatoes

\begin{tabular}{|l|l|}
\hline Sample & Solid matter (\%) \\
\hline Organic tomato & 5.866 \\
\hline conventional tomato & 5.821 \\
\hline
\end{tabular}

The results show that there is no significant difference between organic and conventional tomatoes with respect to solid matter.

DPPH Method: DPPH method is a simple, economical and widely used method to evaluate the antioxidant activity of food samples (Sagar K and Singh R P, 2011) ${ }^{[8]}$. The results are shown in Fig 2.

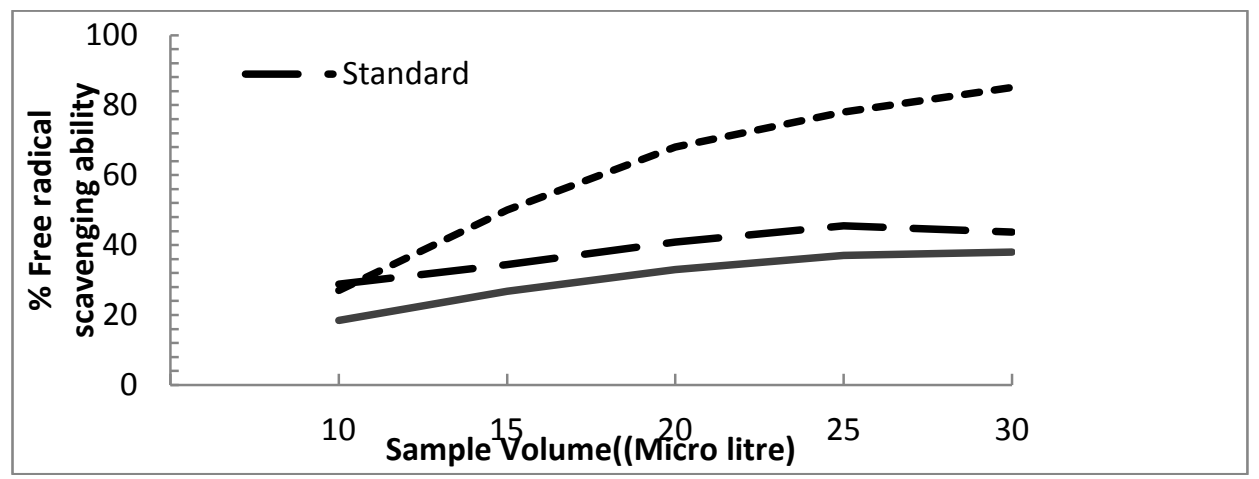

Fig 2: Percent Antioxidant activity using DPPH Method

As the concentration of the sample increased, the free radical quenching ability also increased in case of both organic and conventional tomatoes. The results show that organic tomatoes have significantly $(\mathrm{p}<0.05)$ higher free radical scavenging ability than conventional tomatoes. 
$\beta$ Carotene bleaching method: The absorbance values at $470 \mathrm{~nm}$ are shown below.

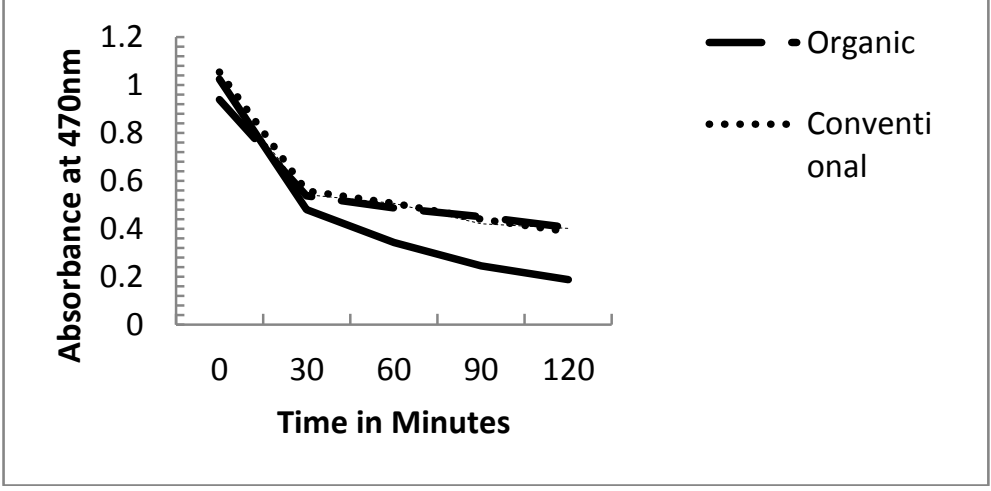

Fig 3: Absorbance of samples by $\beta$ Carotene bleaching method.

The antioxidant activity of the sample was evaluated by $\beta$ Carotene bleaching method in which oxidation of $\beta$ Carotene in presence of linoleic acid takes place. The results show that absorbance decreases with time and there is a steep fall in absorbance in case of control and a slow decrease in case of standard. The results show that both organic and conventional tomatoes are comparable to the standard although conventional tomatoes have a slightly higher absorbance (lower antioxidant activity) than organic tomatoes. Antioxidant activity was calculated using the formula Antioxidant activity $(\%)=100\left\{1-(\mathrm{A} \circ-\mathrm{At}) /\left(\mathrm{A}^{\circ}{ }^{\circ} \mathrm{\circ}-\mathrm{A}^{\circ} \mathrm{t}\right)\right\}$ where $\mathrm{A} \circ$ and $\mathrm{A}^{\circ}$ absorbance values measured at zero time of the incubation of the test sample and control respectively. Organic tomatoes have a significantly higher antioxidant activity than that of conventional tomatoes (Table.2).

Table 2: Antioxidant activity of organic and conventional tomato by $\beta$ Carotene bleaching method.

\begin{tabular}{|l|l|}
\hline Sample & Antioxidant activity $(\%)$ \\
\hline Organic tomato & 36.51 \\
\hline Conventional tomato & 20.29 \\
\hline
\end{tabular}

Kaur C and Harish C (2002) ${ }^{[9]}$ have found the tomato has $70.8 \%$ (Ethanol extract) and 56.3\% (water extract) antioxidant activity using a model system consisting of $\beta$ Carotene-linoleic acid.The difference between their result and the present study might be due to differences in the methodology or the difference in the solvent used for extraction of the sample.

Linoleic acid emulsion system-thiocyanate method:

Table 3: Inhibition to peroxide formation by Linoleic acid emulsion system-thiocyanate method.

\begin{tabular}{|l|l|}
\hline Sample & $\begin{array}{l}\text { Percent inhibition to peroxide } \\
\text { formation }\end{array}$ \\
\hline Conventional tomato & 93.2 \\
\hline $\begin{array}{l}\text { Organic } \\
\text { tomato }\end{array}$ & 92.4 \\
\hline Standard & 92 \\
\hline
\end{tabular}

The results reveal that both organic as well as conventional tomatoes have a high capacity to inhibit peroxide formation. But there is no significant difference between percent inhibition to peroxide formation among organic tomato, conventional tomato or standard (Gallic acid).

Ferric-reducing antioxidant power (FRAP): In this method ferric salt is used as an oxidant. The ferric reducing power expressed in terms of trolox equivalent is shown below.

Table4: Antioxidant activity by FRAP method

\begin{tabular}{|l|l|}
\hline Sample & antioxidant activity (Mol/g of dry weight) \\
\hline Organic tomato & 8.13 \\
\hline Conventional tomato & 7.70 \\
\hline
\end{tabular}

Antioxidant activity expressed in terms of trolox equivalent is slightly higher $(5 \%)$ in case of organic tomato when compared to that of conventional tomato. A systematic screening of antioxidants in foods was done by Bente $\mathrm{L} \mathrm{H}$ et al $(2002)^{[10]}$. The FRAP values expressed in terms of $\mathrm{m}$ mol of antioxidants $/ 100 \mathrm{~g}$ of fresh weight of edible portion were, Cherry tomato-0.34, Plum tomato-0.24, Mali tomato 0.34 respectively. Boxin et al $(2002)^{[11]}$ have found the FRAP value of freeze dried tomato ranged from $40-83 \mu$ molTrolox equivalent/g. The 
antioxidant activity of tomato was found to be highest of the 10 vegetables studied by Raghu et al $(2011)^{[12]}$.There is a lot of variation among the studies indicating that varietal difference, season, soil type, climatic conditions, plant nutrition, methodology employed for analysis, particularly the solvent used for extraction influence the result.

Table 5: Summary of different methods of antioxidant capacity estimations

\begin{tabular}{|l|l|l|l|l|}
\hline Sample & DPPH method & $\begin{array}{l}\beta \text { Carotene bleaching } \\
\text { method }\end{array}$ & $\begin{array}{l}\text { Linoleic acid emulsion } \\
\text { system-thiocyanate } \\
\text { method }\end{array}$ & $\begin{array}{l}\text { Ferric-reducing } \\
\text { antioxidant } \\
\text { (FRAP): }\end{array}$ \\
\hline Organic & $+_{++*}^{*}$ power & +++ \\
\hline Conventional & ++ & $+_{+*}^{*}$ & +++ & ++ \\
\hline
\end{tabular}

$+++*$ Higher and Significant

+++ Higher but not significant

++ Lower

From the above table it can be noted that organic tomatoes have higher antioxidant capacity compared to conventional tomatoes. DPPH radical scavenging ability, $\beta$ Carotene bleaching ability are significantly higher but Linoleic acid emulsion system-thiocyanate method, Ferric-reducing antioxidant power although are higher in case of organic tomatoes the difference is not significant.

The results are in agreement with the results of 3 year comparison of organic tomatoes (Burbank and Ropreco ) and conventional tomatoes, in which they have shown that organic tomatoes have higher quercetin, kaempferol, total phenolics, ascorbic acid compared to conventional tomatoes (Alexander W C et al 2006) ${ }^{[13]}$. And study by Catherine Caris-Veyrat ${ }^{[14]}$ has shown that organic tomatoes had higher vitamin $\mathrm{C}$, carotenoids, and polyphenol contents (except for chlorogenic acid) than conventional tomatoes. One of the limitations of the present study was that the analysis of the antioxidant constituents was not done to point out the difference in the chemical composition of the organic and conventional tomatoes. It is also to be noted that synergistic effect of the constituents might have also contributed to the difference between organic and conventional tomatoes. Further studies are needed in this direction.

\section{Conclusion}

Tomato is one of the commonly used vegetables with high antioxidant capacity. Organic tomatoes have higher antioxidant ability than conventional tomatoes. These differences are significantly higher in case of DPPH method, $\beta$ Carotene bleaching method but not significant in case of Linoleic acid emulsion systemthiocyanate method and Ferric-reducing antioxidant power.

\section{Acknowledgement}

This work is part of the project work under Summer Research Fellowship Programme 2011, of Indian Academy of Sciences, Bangalore, Indian National Science Academy, New Delhi: and The National Academy of Sciences, Allahabad. We are thankful to Dr A G Appu Rao and Dr Sridevi Annapurna Singh of the Department of Protein Chemistry and Technology of CFTRI, Mysore for their guidance in carrying out this project.

\section{References:}

[1]. Halliwell, B., 1996. Oxidative stress, nutrition and health: Experimental strategies for optimization of nutritional antioxidant intake in humans. Free. Rad .Res., 25(1):57-74.

[2]. KirstieCanene-Adams, Jessica, K. Campbell, Susan Zaripheh, Elizabeth H Jeffery, and John W Erdman, 2005. Tomato as a functional food. J.Nutr. 135: 1226-1230.

[3]. Espin, J. C., Cristina, S. R., and Wichers, H. J, 2000.Characterization of the Total Free Radical Scavenger Capacity of Vegetable Oils and Oil Fractions Using 2,2-Diphenyl-1-picrylhydrazyl Radical. J.Agic. Food. Chem., 48: 648-656

[4]. Hidalgo, M. E., Fernandez, E., Quilhot, W., and Lissi, E, 1994.Antioxidant activity of depsides and depsidones.Phytochemistry.37: $1585-1587$.

[5]. Haraguchi, H, Hashimoto, K. and Yogi, A. 1992. Antioxidant substancesin leaves of polygonumhydropiper. J.Agic. Food. Chem., 40: $1349-1351$.

[6]. Yen, G. C. and Hsieh, C. L., 1998. Antioxidant activity of extracts from Du-zhong (Eucommiaulmonides) toward various peroxidation models in vitro. J.Agic. Food. Chem., 46: 3952-3957.

[7]. Benzie, I. F., and Strain, J. J. 1996. The ferric reducing ability of plasma as a measure of "antioxidant power" the FRAP Assay.Anal.Biochem., 239: 70-76.

[8]. Sagar, B. K, and Singh R. P. ,2011. Genesis and development of DPPH method of antioxidant assay. J. Food .Sci. Techn., 48(4):412-422.

[9]. KaurCharanjit, and Harish Kapoor, 2002. Antioxidant activity and total phenolic content of some Asian vegetables. International Journal of Food Science and Technology. 37: 153-161.

[10]. Bente, L.Halvorsen, et al 2002. A systematic screening of total antioxidants in dietary plants. J. Nutr., 132: 461-471. 
[11]. 11.Boxin,Ou, Dejian Huang, Maureen Hampsch-Woofill, Judith A. Flanagan and Elizabeth K Deemer,. 2002. Analysis of antioxidant activities of common vegetables employing ORAC and FRAP assays: A comparative study. J.Agic. Food. Chem., 50: 3122-3128.

[12]. Raghu, K. L., Ramesh C. K, Srinivasa, T.R. and Jamuna, K. S. 2011. Total antioxidant capacity in aqueous extracts of some common vegetables. Asian. J. Exp. BiolSci.2(1): 58-62.

[13]. Alexander, W. C., Linh Bui, Erica N. C. Renaud, Mark Van Horn, and Alyson E. Mitchell, 2006. Three year comparison of the content of antioxidant micro constituents and several quality characteristics in organic and conventionally managed tomatoes and bell peppers. J.Agic Food Chem., 54: 8244-8252.

[14]. Catherine Caris-Veyrat,Marie-JosèpheAmiot, Viviane Tyssandier, Dominique Grasselly, Michel Buret, Michel Mikolajczak, Jean-Claude Guilland, Corinne Bouteloup-Demange, and Patrick Borel 2004. Influence of Organic versus Conventional Agricultural Practice on the Antioxidant Microconstituent Content of Tomatoes and Derived Purees; Consequences on Antioxidant Plasma Status in Humans J. Agric. Food Chem., 52 (21), 6503-6509. 